\title{
THE ACTIONS OF ULTRASOUND ON THE MYELINATED NERVE, THE SPINAL CORD AND THE BRAIN
}

\author{
SADAYUKI F. TAKAGI, SYOJI HIGASHINO, TATSUAKI SHIBUYA \\ AND NOBUTAKA OSAWA* \\ Department of Phy'siology, School of Medicine, Gunma University, Maebashi, Japan
}

The action of ultrasound on the living things have been actively studied since the pioneer work of Wood-Loomis (1927). It was studied on the nervous tissues by Fry, Wulff, Tucker and Fry (1950), Oka, Okumura, Yokoi and Miyoshi (1952), Barnard, Fry, Fry and Krumins (1955) and Ballantine, Hueter, Nauta and Sosa (1956). The thermal aspect of the actions of ultrasound on the muscle and the nervous tissue was studied by Herrick (1952), and Welkowitz and Fry (1957). The physio-chemical aspect of the actions of ultrasound on the living matters was done by Lehmann (1952). Which one of these actions plays a main role has long been a center of discussion. The above studies concerned the destructive action of high intensity ultrasound, and the stimulative action of ultrasound has hardly been studied. This paper is mainly concerned with the stimulative action of ultrasound on the myelinated nerve, the spinal cord and the brain. The results are compared with the effect of temperature on the spinal cord. The mechanism of the actions of ultrasound is discussed.

\section{METHODS}

\section{Ultrasonic generator and recording apparatus}

In order to generate a focused ultrasound, an $1 \mathrm{MC} \mathrm{X}$-cut concave quartz crystal (diameter: $42 \mathrm{~mm}$.) was attached to the bottom of a beaker filled with Ringer's solution and excited by an $1 \mathrm{MC}$ oscillator. A focused ultrasound thus generated was irradiated on the nerve tissues from the bottom upwards (fig. 2). The focal distance was $120 \mathrm{~mm}$. The relation between the plate voltage of the ultrasonic generator and the ultrasonic intensity is shown in fig. 1 . In order to generate a plane ultrasound, a $3 \mathrm{MC} \mathrm{X}$-cut flat quartz crystal (diameter: $30 \mathrm{~mm}$.) was used. It was irradiated on the nerve tissues from above. The change of nerve action potentials and spinal reflex discharges were observed and recorded on a cathode ray oscilloscope (fig. 2). The temperatures of Ringer's solution used were initially $13-15^{\circ} \mathrm{C}$.

\footnotetext{
Received for publication September 13, 1959.

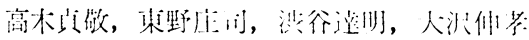

* Present address: Department of Microbiology, School of Medicine, Gunma University, Maebashi.
} 


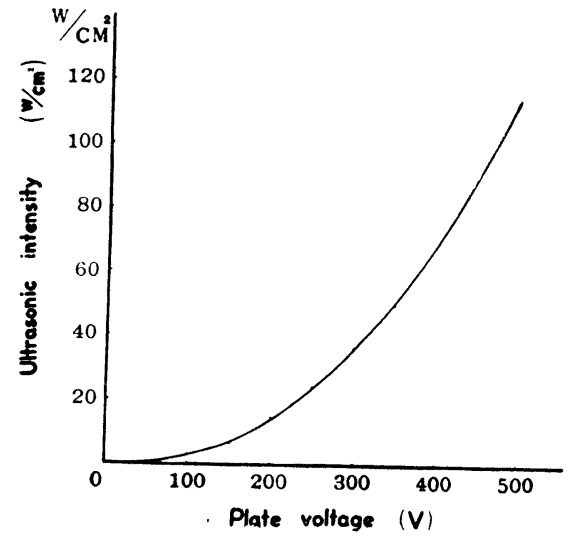

FIG. 1. The relation between the plate voltage of the ultrasonic oscillator and the intensity of the focused ultrasound generated. These were calculated from the plate voltage and the plate current of the generator.

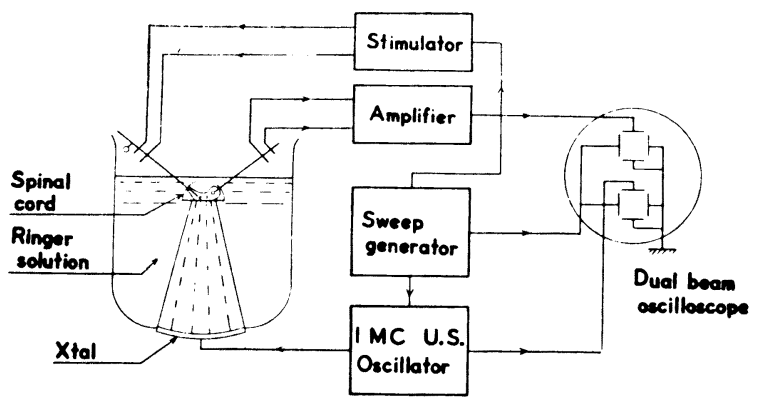

FIG. 2. A schematic diagram of the stimulating and the recording apparatus when a spinal cord was irradiated with ultrasound. A dorsal root was stimulated and reflex or spontaneous discharges were recorded from a ventral root. A part of the output of the oscillator was led to one channel of a dual beam oscilloscope to show the time of irradiation. The oscilloscope, the ultrasonic oscillator and the stimulator were all synchronized by a sweep generator.

\section{Measurement of a rise of temperature inside a frog muscle}

A thermistor of injection needle type (diameter: $1.5 \mathrm{~mm}$.) was used to measure the temperature inside a muscle. It was inserted into a frog muscle which was placed at the focal point of the focused ultrasound. The changes of temperature were measured by an ammeter or by a cathode ray oscilloscope (fig. 10).

\section{Material}

a) A sciatic nerve of a toad (Bufo vulgaris japonica) was used. The one end of the nerve was stimulated and the action potential was led from the other end to a cathode ray oscilloscope for recording. The nerve was stretched by pulling both ends of the nerve towards the opposite directions. The middle part of the nerve was pushed down into Ringer's solution with a stimulating 
and a recording silver electrodes which are several centimeter apart. The central part of the nerve between the two electrodes was placed just at the focal point of ultrasound which was irradiated from below. Thus, the movement of the nerve due to hydrodynamical flow in the ultrasonic field was eliminated.

b) The spinal cord of a toad was excised and cut into halves along the mid-line. One of the halves was pinned on a cork plate with the cut surface downwards. It was immersed in Ringer's solution and a focused ultrasound was irradiated from below. Before, during and after irradiation, a dorsal root was stimulated and a reflex discharge was recorded from a ventral root. In order to maintain the reflex discharge, oxygen was constantly bubbled in Ringer's solution.

c) A bullfrog tadpole and a frog were decapitated and their brains were exposed. A plane ultrasound was irradiated from above onto the brain. The preparation was fixed on a cork plate which was set deeply in Ringer's solution. Before and after irradiation, Ringer's solution was decreased so that brain wave might be recorded from a small exposed part of the brain surface.

RESULTS

\section{The stimulative action of ultrasound on the myelinated nerve}

It was observed that the spike potential was enlarged initially, but it was eventually inhibited after repetitive irradiation of ultrasound (fig. 3). The increase of the spike potential height was about 10 to $30 \%$ in case that the intensity of ultrasound was about $16 \mathrm{~W} / \mathrm{cm}^{2}$. However, after irradiation of ultrasound of over $35 \mathrm{~W} / \mathrm{cm}^{2}$, the spike potentials were inversely inhibited. From these facts, it was found that the stimulative effect on myelinated nerves occurs during and after irradiation for several minutes with ultrasound of about $16 \mathrm{~W} / \mathrm{cm}^{2}$. This effect could be repeatedly observed. This seems to be a threshold intensity with a safety factor for stimulative action.

1

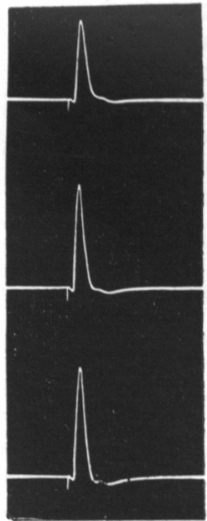

4

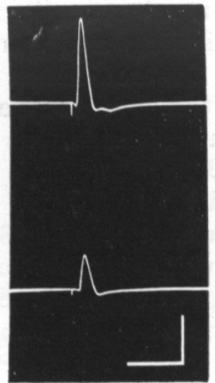

FIG. 3. Ultrasonic effect on the action potential of a frog sciatic nerve. 1. Control. 2, 3. After ultrasonic irradiation of $16 \mathrm{~W} /$ $\mathrm{cm}^{2}$, spike heights were enlarged. 4, 5 . After ultrasonic irradiation of $35 \mathrm{~W} / \mathrm{cm}^{2}$, spike heights were decreased. Irradiation time is $2 \mathrm{~min}$. in all. Voltage and time calibration, $1 \mathrm{mV}$ and $5 \mathrm{msec}$. 


\section{The stimulative action of ultrasound on the spinal cord}

The action of ultrasound on the reflex discharges produced by dorsal root stimulation was studied (fig. 4). Only the spinal cords which did not show spontaneous ventral discharges were used. After $20 \mathrm{sec}$. irradiation of $3.2 \mathrm{~W} / \mathrm{cm}^{2}$ ultrasound, small spontaneous discharges appeared on the ventral root. In that stage, it was found that the reflex discharges by dorsal root stimulation were significantly increased. When ultrasound of higher intensity $\left(6.83 \mathrm{~W} / \mathrm{cm}^{2}\right)$ was irradiated, spontaneous discharges again appeared continuously during and after irradiation. But when they disappeared, it was found that the reflex discharges were slightly less than those before irradiation. This indicates that a slight inhibitory action had already begun even with ultrasound of this intensity. Though a decrease of the reflex discharges, namely a slight inhibitory effect was already observed, spontaneous discharges still increased during and after irradiation of strong ultrasound $\left(24.0 \mathrm{~W} / \mathrm{cm}^{2}\right)$. The same phenomenon was again observed when ultrasound of higher intensity $\left(35.9 \mathrm{~W} / \mathrm{cm}^{2}{ }^{2}\right)$ was irradiated. The decrease of the spontaneous discharges was only observed by irradiation with ultrasound of over 50 to $68 \mathrm{~W} / \mathrm{cm}^{2}$. Spontaneous ventral root discharges during and after $1 \mathrm{sec}$. irradiation are shown in fig. 5 . It was found
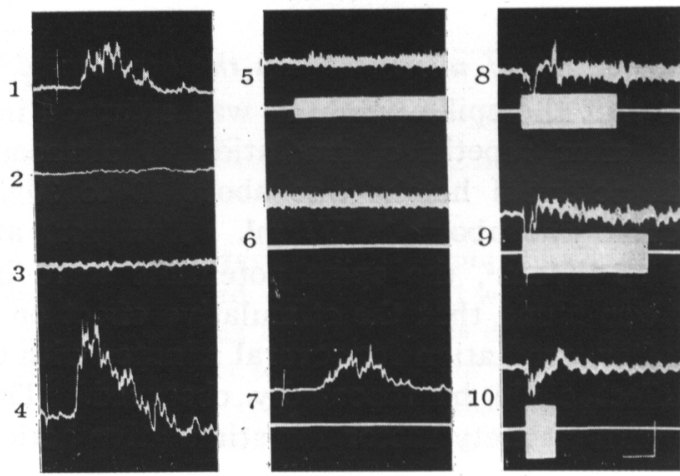

FIG. 4. The effect of ultrasound on the spinal activity. The upper channel shows the ventral root discharges and the lower channel does the beginning and duration of irradiation in $5,8,9$ and 10 . 1 . Control reflex discharges when a dorsal root was stimulated. 2. Control. Without stimulation of a dorsal root, no spontaneous discharges appeared on a ventral root. 3. Spontaneous discharges appeared just after irradiation with $3.24 \mathrm{~W} / \mathrm{cm} .{ }^{2}$ ultrasound. 4. Reflex discharges increased immediately after 3. 5. Generation of spontaneous discharges during irradiation with 6.83 $\mathrm{W} / \mathrm{cm}^{2}{ }^{2}$ ultrasound in the upper channel. 6. Spontaneous discharges continued after cessation of irradiation. 7. Reflex discharges were slightly inhibited just after 5 . 8. Spontaneous discharges were still actively generated by irradiation with $24.0 \mathrm{~W} / \mathrm{cm}^{2}$ ultrasound. 9. Spontaneous discharges decreased after irradiation with $35.9 \mathrm{~W} / \mathrm{cm} .^{2}$ ultrasound. 10. Spontaneous discharges appeared only slightly by irradiation with $68.8 \mathrm{~W} / \mathrm{cm}^{2}{ }^{2}$ ultrasound. Voltage and time calibration, $100 \mu \mathrm{V}$ and $1 \mathrm{sec}$. 
that there was a latent period between the onset of irradiation and the appearance of the spontaneous discharges, and that there is an inverse linear relation between the two (fig. 6). Fig. 7 shows the duration of the spontaneous discharges generated by $1 \mathrm{sec}$. ultrasonic irradiation of various intensities. When the intensity was increased, after-discharge began to appear (fig. 7-2) and its duration increased (fig. 7-3, 4). But beyond a certain intensity, the duration of the after-discharge began to decrease (fig. 7-5).

1
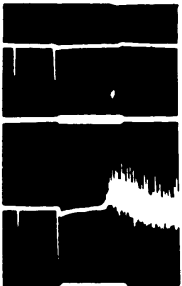

2

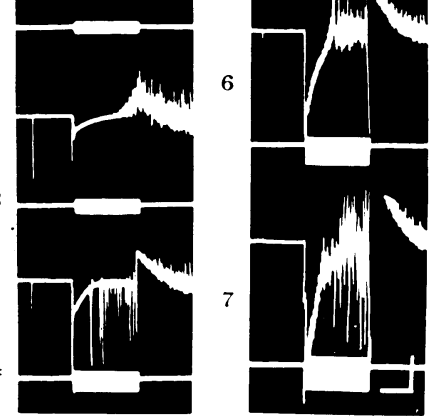

5

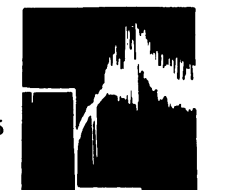

FIG. 5. The upper channel shows the appearance of ventral spontaneous discharges by $1 \mathrm{sec}$. irradiation with ultrasound of various intensities. The lower channel does the intensity and duration of ultrasound. Ultrasonic intensities are respectively $0.5 \mathrm{~W} / \mathrm{cm}^{2}{ }^{2}$ in $1,3.24 \mathrm{~W} / \mathrm{cm}^{2}$ in $2,6.83 \mathrm{~W} / \mathrm{cm}^{2}{ }^{2}$ in $3,13.5 \mathrm{~W} / \mathrm{cm} .^{2}$ in $4,24.0$ $\mathrm{W} / \mathrm{cm}^{2}{ }^{2}$ in $5,35.9 \mathrm{~W} / \mathrm{cm}^{2}{ }^{2}$ in $6,50.0 \mathrm{~W} / \mathrm{cm}^{2}{ }^{2}$ in 7 . It is seen that the latent period of the discharges became shorter when the intensity was increased. Voltage and time calibration, $500 \mu \mathrm{V}$ and $0.5 \mathrm{sec}$.

1

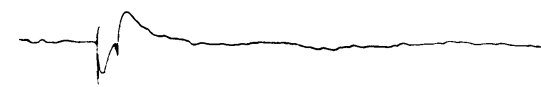

2

3<smiles>[CH]</smiles>

4

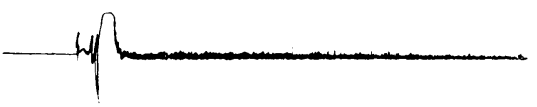

5

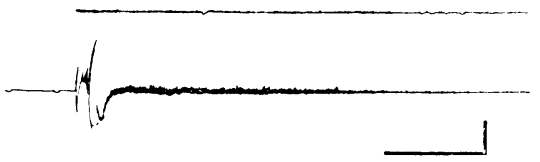

FIG. 7

FIG. 6. The relation between the latent period and the plate voltage in the experiment of fig. $\bar{j}$.

FIG. 7. The duration of spontaneous discharges generated after $1 \mathrm{sec}$. irradiation of ultrasound of intensity of $13.5 \mathrm{~W} / \mathrm{cm}^{2}$ in $1,24.0 \mathrm{~W} / \mathrm{cm}^{2}$ in $2,35.9 \mathrm{~W} / \mathrm{cm} .^{2}$ in $3,50.0 \mathrm{~W} / \mathrm{cm} .{ }^{2}$ in 4 and $68.8 \mathrm{~W} / \mathrm{cm}^{2}$ in 5 . Voltage and time calibration, $1 \mathrm{mV}$ and $5 \mathrm{sec}$. 
When a spinal cord immersed in Ringer's solution with $0.01 \%$ strychnine was irradiated, spontaneous discharges appeared during irradiation, but the after-discharges which appeared in normal Ringer's solution were not observed. The mechanism of these different results remains to be clarified yet. It is known that strychnine raises markedly the excitability of spinal cells. Nevertheless, it was found that the intensities of ultrasound at which spontaneous discharges began to appear were not different in normal Ringer's solution from in strychnine-Ringer's solution. This phenomenon is also open to a question in the present stage of this research.

\section{The stimulative action of ultrasound on the brain waves}

The cerebrum of a bullfrog tadpole was irradiated from above with a plane ultrasound. When a weak ultrasound $\left(9.3 \mathrm{~W} / \mathrm{cm}^{2}{ }^{2}\right)$ was irradiated, the brain wave became very irregular but increased its magnitude (fig. 8). Considering the results on the spinal cord, this may be explained that the activity of the brain cells was increased. But, when the same ultrasonic irradiation was repeated, the brain waves were inversely decreased and finally disappeared. It is known that a frog olfactory bulb shows a regular potential wave of about 6 c.p.s. especially after the application of $0.1-0.5 \%$ nicotine solution (Libet and Gerard, 1938). When irradiated, the regular nicotine wave became irregular (desynchronization-effect). The amplitudes of the wave at first increased, but soon decreased. When nicotine was applied again, the brain wave restored its regularity considerably (fig. 9). The same phenomenon was observed in the brain of a bullfrog tadpole. Thus, the action of nicotine and ultrasound were found competitive. The effect of nicotine on the brain wave was explained

1

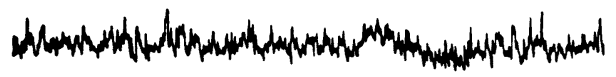

2

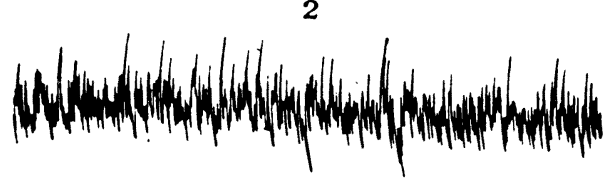

3
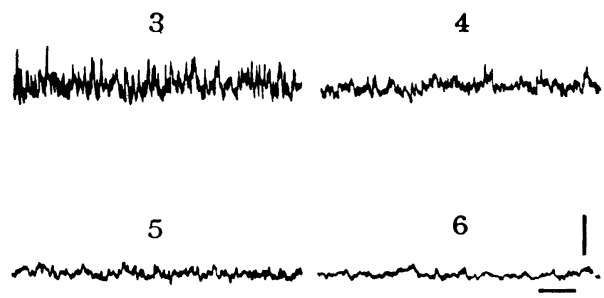

to be due to the synchronization of action potentials of many cells which constitute the brain wave. Therefore, it may be supposed that weak ultrasound raises the excitability of brain cells, but obstructs synchronization among the cells.

FIG. 8. The action of ultrasound on the brain waves of a bullfrog tadpole. 1. Control. 2. After irradiation (3 MC, $9.3 \mathrm{~W} / \mathrm{cm}^{2}, 2 \mathrm{~min}$.), marked increase of the brain wave was observed. 3. After 2nd irradiation. 4. After 3rd irradiation. 5. After 4 th irradiation. 6. After 5th irradiation, the brain wave was markedly inhibited. Voltage and time calibration, $50 \mu \mathrm{V}$ and $1 \mathrm{sec}$. 

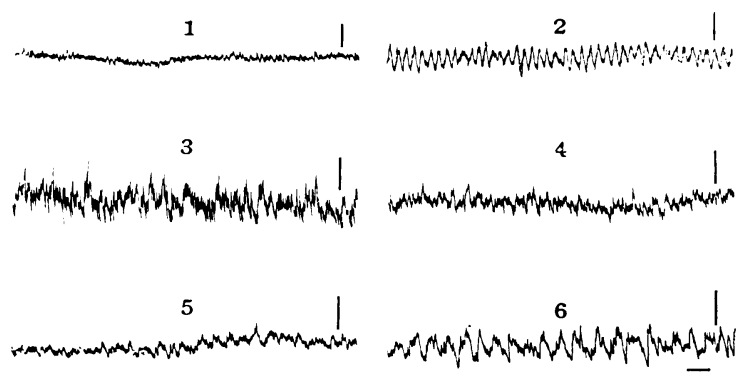

FIG. 9. The action of ultrasound and nicotine on the brain waves of a bullfrog tadpole. 1. Control. 2. After the application of nicotine, regular wave appeared. 3. After ultrasonic irradiation ( $3 \mathrm{MC}, 9.3 \mathrm{~W} / \mathrm{cm}^{2}, 2 \mathrm{~min}$.), the brain wave was augmented but its regularity was lost. $4.10 \mathrm{~min}$. after irradiation, the brain wave became smaller. 5. Immediately after 2 nd application of nicotine. 6.2 min. after 5 , regularity was considerably restored. Voltage and time calibration, $50 \mu \mathrm{V}$ and $1 \mathrm{sec}$.

\section{The rise of temperature by ultrasonic irradiation in muscle}

The rise of temperature in muscle due to $1 \mathrm{sec}$. irradiation with a focused ultrasound was measured and found to be about $5^{\circ} \mathrm{C}$. at the intensity of 13.5 $\mathrm{W} / \mathrm{cm}^{2}, 6^{\circ} \mathrm{C}$. at that of $35.0 \mathrm{~W} / \mathrm{cm}^{2}$ and $10^{\circ} \mathrm{C}$. at that of $68.8 \mathrm{~W} / \mathrm{cm}^{2}$ (fig. 10). The rise of temperature was exponential at low intensity, but was abrupt and had some flexions beyond the intensity of $13.5 \mathrm{~W} / \mathrm{cm}^{2}$. The flexions may be produced by the appearance and disappearance of bubbles formed by cavitation of ultrasonic field. In the case of $5 \mathrm{~min}$. irradiation (fig. 11), temperature rapidly rose for the first $1 \mathrm{~min}$., and then rose gradually. The rise was found to be about $5^{\circ} \mathrm{C}$. at $24.0 \mathrm{~W} / \mathrm{cm}^{2}(250 \mathrm{~V}), 10^{\circ} \mathrm{C}$. at $50.0 \mathrm{~W} / \mathrm{cm}^{2}(350 \mathrm{~V})$, and $20^{\circ} \mathrm{C}$.

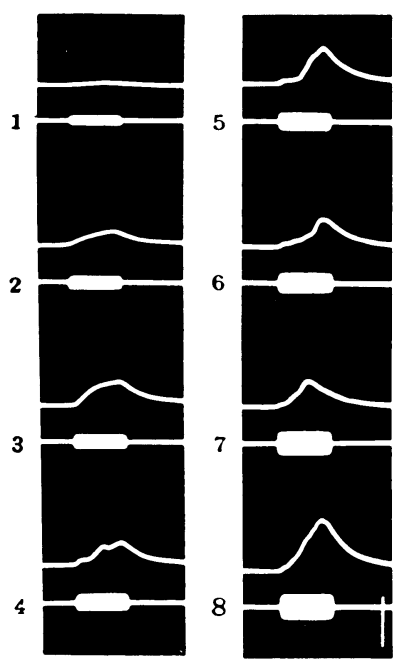
at $68.8 \mathrm{~W} / \mathrm{cm}^{2}(400 \mathrm{~V})$. Thus, it was presumed that the rise of temperature at the ultrasonic intensities which produced a stimulative action was less than $10^{\circ} \mathrm{C}$. Fry et al. (1950) found that the rise of temperature due to irradiation with $1 \mathrm{MC}$ ultrasound of $35 \mathrm{~W} / \mathrm{cm}^{2}$ was about $1.8^{\circ} \mathrm{C} /$ sec. in the sciatic nerve, the spinal cord and the muscle, but it was about $55^{\circ} \mathrm{C} / \mathrm{sec}$. in the

FIG. 10. The upper channel shows a rise of temperature in a frog muscle by $1 \mathrm{sec}$. irradiation. The lower channel shows the intensity and duration of irradiation. The intensity of the focused ultrasound is $0.5 \mathrm{~W} / \mathrm{cm}^{2}$ in $1,3.24 \mathrm{~W} / \mathrm{cm}^{2}$ in $2,6.83 \mathrm{~W} / \mathrm{cm}^{2}$ in $3,13.5$ $\mathrm{W} / \mathrm{cm}^{2}$ in $4,24.0 \mathrm{~W} / \mathrm{cm}^{2}$ in $5,35.9 \mathrm{~W} / \mathrm{cm}^{2}$. in $6,50.0$ $\mathrm{W} / \mathrm{cm} .^{2}$ in 7 and $68.8 \mathrm{~W} / \mathrm{cm}^{2}$ in 8 . A vertical line on the right bottom shows $10^{\circ} \mathrm{C}$. 


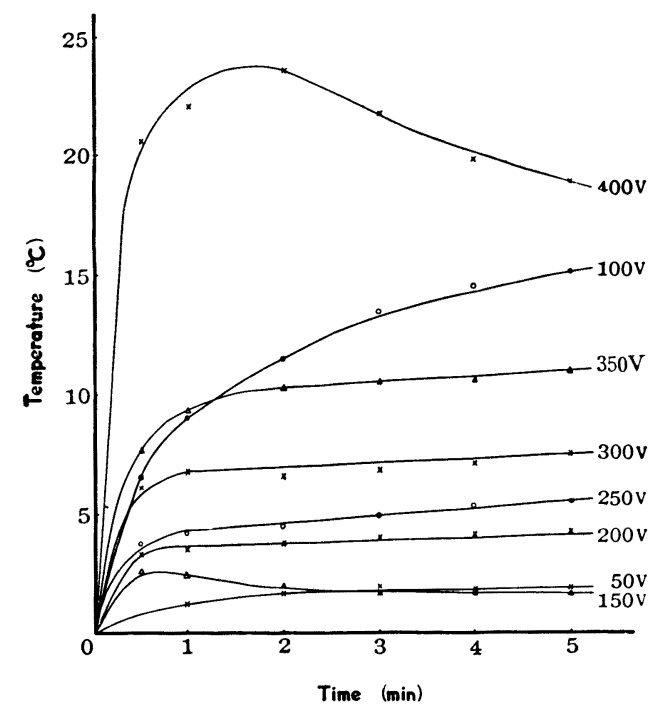

FIG. 11. A rise of temperature in a frog muscle by irradiation with ultrasound of various intensities and durations. In the case of $100 \mathrm{~V}$, an extraordinary curve was obtained. This may be so because the focal distance was changed at this intensity much more than at the other intensities.

bone. Though rise of temperature was measured only in the muscle in our experiment, it was presumed from the findings by Fry et al. (1950) that the rise of temperature of about the same degree as in the muscle will be found in the myelinated nerve, the spinal cord and the brain.

It was found that the rise of temperature by irradiation with ultrasound of $35 \mathrm{~W} / \mathrm{cm}^{2}$ is in our experiment about 3 times bigger than that found by Fry et al. at the same intensity. This difference may be due to difference in the methods of measurement of the ultrasonic intensity. The intensity was calculated from the plate voltage and the plate current of a generator in our experiment.

5. The effect of temperature on the spinal cord

In order to analyze the action of ultrasound on nerve tissues, the effect of temperature was studied on the spinal reflex activity between $13^{\circ} \mathrm{C}$. and $30^{\circ} \mathrm{C}$.

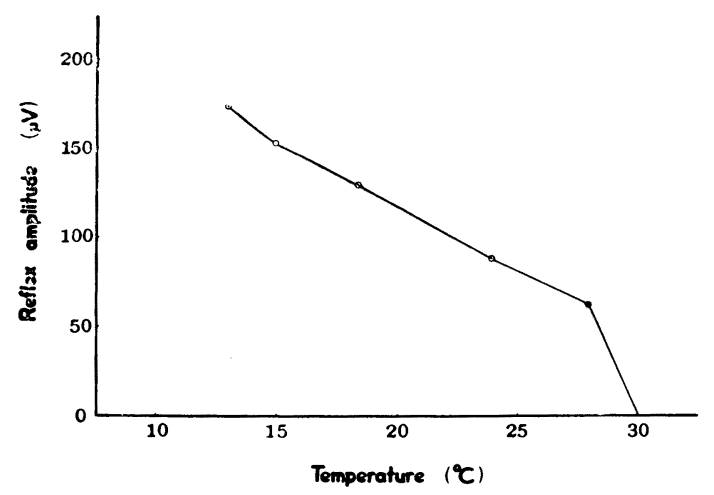

A spinal cord was immersed for longer than $5 \mathrm{~min}$. in Ringer's solution of a certain temperature, and the changes of the reflex discharges were recorded. When temperature was raised, the reflex discharges gradually decreased

FIG. 12. Decrease of the magnitudes of the reflex discharges when the temperature of Ringer's solution was raised from $13^{\circ} \mathrm{C}$. to $30^{\circ} \mathrm{C}$. No increase of the reflex discharges was found. 
their amplitude (fig. 12). Neither increase of the reflex discharges nor the appearance of spontaneous discharges could be seen. Thus, the effect of temperature is entirely different from that of ultrasound. It is therefore presumed that the main role of ultrasonic actions on the spinal cord is not played by a rise of temperature, but by the other actions of ultrasound.

\section{DISCUSSION}

Fry et al. (1950) studied the effect of ultrasound on the action potential of a frog sciatic nerve and found no detectable changes in the form and the size of the potential. They also found similar negative results on the leg nerve of a crayfish. In our studies, it was found on the myelinated nerve, the spinal cord and the brain that ultrasound has a stimulative effect under a certain intensity, beyond which it has an inhibitory effect. Besides, when irradiation was repeated, it was found that the stimulative action increased at first, but it was finally replaced by an inhibitory action, both probably due to the summation of ultrasonic after-effect. Such an after-effect of ultrasound has generally been found on various living things. Our findings on frog sciatic nerves are not coincident with the ones by Fry et al., in that an augmentative action was found at low intensity $\left(16 \mathrm{~W} / \mathrm{cm}^{2}\right)$ and an inhibitory one at high intensity $\left(35 \mathrm{~W} / \mathrm{cm}^{2}{ }^{2}\right)$ in our experiment, whereas they found only negative results. On the other hand, their finding on the spontaneous discharges of a ventral nerve cord of a crayfish after irradiation with ultrasound is coincident with our studies on the spontaneous ventral root discharges in that weak ultrasound has a stimulative action. As indicated in the beginning, it has been shown by other workers that ultrasound of high intensity has an inhibitory (destructive) action on the living tissues. Thus, it is concluded that ultrasound has a stimulative action at low intensity, but an inhibitory action at high intensity on the nerve tissues and the muscle.

\section{SUMMARY}

1. The action of ultrasound was studied on the sciatic nerve of a frog, the spinal cord of a toad, and the brain of a bullfrog tadpole and a frog. The results were compared with the effect of temperature.

2. The action potential of a myelinated nerve was enlarged by irradiation with ultrasound of about $16 \mathrm{~W} / \mathrm{cm}^{2}$, but it was inhibited by irradiation with that of higher intensity.

3. The reflex discharges of the spinal cord were increased by irradiation with ultrasound of about $3 \mathrm{~W} / \mathrm{cm} .^{2}$. But they were inhibited at higher intensity (beyond $6.83 \mathrm{~W} / \mathrm{cm}^{2}$ ).

4. The brain wave was augmented by irradiation with weak ultrasound, but they were decreased by repeated irradiation.

5 . It was concluded that ultrasound has a stimulative action at low intensity, but has an inhibitory action at high intensity on the nerve tissues and the muscle. However, when ultrasound with a stimulative action was repetitively applied, it eventually produced an inhibitory action. 
6. Spontaneous discharges appeared on the spinal ventral root by ultrasonic irradiation. Up to a certain ultrasonic intensity, an inverse linear relation was found between the intensity and the latent period of the discharge.

7. The rise of temperature was measured in a frog muscle during and after ultrasonic irradiation. It was found to be less than $10^{\circ} \mathrm{C}$. at the ultrasonic intensities which produced a stimulative action.

8. By raising the temperature of Ringer's solution, the effect of temperature was studied on the spinal reflex activity. The results were entirely different from the ultrasonic actions on the spinal cord. It was therefore presumed that the main role of the actions of ultrasound is not played by a rise of temperature, but by the other actions of ultrasound.

The authors are very much indebted to the Rockefeller Foundation for the contribution of some apparatus used in this experiment. This work was carried out with the aid of a grant for scientific research from the Ministry of Education.

\section{REFERENCES}

1. ARIGA, A. Application of ultrasound in medical region. I, II and III. Medical bulletin of Nippon University 11: 1-10, 71-84, 143-151, 1956.

2. Ballantine, H., Hueter, T. F., Nauta, W. J. H. and Sosa, D. M. Nervous tissue destroyed by focused ultrasound. J. exper. Med. 104: 337-360, 1956.

3. BARnARD, J. W., Fry, W. J., FRY, F. J. AND KRUmins, R. F. Effects of high intensity ultrasound on the central nervous system of the cat. J. comp. Neurol. 103: 459, 1956.

4. Bowsher, D. Effect of high intensity focused ultrasound on nerve cells in spinal cord of mouse. A.M.A. Arch. Neurol. Psychiat., Chicago. 78: 377-382, 1957.

5. Fry, W. J., WulfF, V. J., TuCKer, D. AND Fry, F. J. Physical factors involved in ultrasonically induced changes in living systems. I. Identification of non-temperature effects. J. Acoust. Soc. Am. 22: 867-876, 1950.

6. Fry, W. J., WUlfF, V. J., TUCKer, D. AND Fry, F. J. Physical factors involved in ultrasonically induced changes in living systems. II. Amplitude duration relations and the effect of hydrostatic pressure for nerve tissue. J. Acoust. Soc. Am. 23: 364368, 1951.

7. Fry, W. J., Mosberg, W. H. JR., Barnard, J. W. AND Fry, F. J. Production of focal destructive lesion in the central nervous systems with ultrasound. J. Neurosurg. 11: 471-478, 1954.

8. HATFIELD, H. S. Ultrasonic absorption and thermal conductivity of muscle. Nature, Lond. 178: 87--88, 1956.

9. HERRICK, J. F. Temperature produced in tissues by ultrasound: Experimental study using various technics. J. Acoust. Soc. Am. 25: 12-16, 1952.

10. LEHMANN, J. F. The biophysical mode of action of biologic and therapeutic ultrasonic reactions. J. Acoust. Soc. Am. 25: 17-25, 1952.

11. LIBET, B. AND GERARD, R. W. Control of the potential rhythm of the isolated frog brain. Am. J. Physiol. 123: 153-169, 1938.

12. OKa, M., OKumura, T., Yokoi, H. And Miyoshi, J. Study of the clinical application of supersonic waves. Clin. Surg. 7: 383-387, 1952.

13. OKumura, T. Study on the influences of ultrasonic waves upon the nervous systems. Jap. J. Psychiat. Neurol. 59: 881-895, 1957.

14. Pohlmann, R., Richiter, R. ANd Parrow, E. Uber die Ausbreitung und Absorption des Ultraschall im menschen Gewebe und therapeutische Wirkung am Ischias und 
Plexusneuralgie. Dtsch. med. Wschr. 65: 251-258, 1939.

15. Pohlmann, R. Die Ultraschalltherapie. Quantitative zur ihren Wirkungsmechanismus. Dtsch. med. Wschr. 73: 373-381, 1948.

16. TAKAGI, T. AND OMURA, $H$. On the mechanism of the brain wave observed in the olfactory bulb of a frog. Med. Sci. 8: 297-306, 1957 (Japanese).

17. Wall, P., Tucker, D., Fry, F. J. AND Mosberg, W. H. The use of high intensity ultrasound in experimental neurology. J. Acoust. Soc. Am. 25: 281-285, 1953.

18. Welkowitz. W. AND FRY, W. J. Effects of high intensity sound on electrical conduction in muscle. J. cell. comp. Physiol. 48: 453-457, 1957.

19. WOOD, R. W. AND LOOMIS, A. L. Physical and biological effects of high frequency sound waves of great intensity. Phil. Mag. 4: 417, 1927. 